\title{
Early Hemodynamic Response Assessment of Stereotactic Radiosurgery for a Cerebral Arteriovenous Malformation Using 4D Flow MRI
}

\author{
(D)C.Q. Li, (D) A. Hsiao, DJ. Hattangadi-Gluth, (D). Handwerker, and (D). Farid
}

\begin{abstract}
SUMMARY: Brain AVMs treated with stereotactic radiosurgery typically demonstrate a minimum latency period of 1-3 years between treatment and nidus obliteration. Assessment of treatment response is usually limited to evaluation of AVM nidus structural changes using conventional MR imaging and MRA techniques. This report describes the use of 4D Flow MRI to also measure radiation-induced hemodynamic changes in a Spetzler-Martin grade III AVM, which were detectable as early as 6 months after treatment.
\end{abstract}

ABBREVIATION: SRS = stereotactic radiosurgery

$\mathbf{S}$ tereotactic radiosurgery (SRS) is an effective treatment option for brain arteriovenous malformations that are not amenable to microsurgical resection or endovascular embolization. Nidus obliteration is thought to result from radiationinduced endothelial cell proliferation causing progressive vessel wall thickening and eventual occlusion. ${ }^{1}$ When successful, this process typically results in a latency period of $1-3$ years between treatment and nidus obliteration, ${ }^{2}$ though the nidus can persist in approximately $20 \%$ of AVMs even 5 years after treatment. $^{3}$

Although MR imaging and MRA have widely supplanted DSA as the mainstay modalities for following AVMs posttreatment, prior studies evaluating their ability to assess the response to SRS have only examined AVM structure, specifically nidus volume. ${ }^{4-8}$ Advanced MRA techniques capable of measuring intracranial flow dynamics, such as 4D Flow MRI (https://www.arterys.com/ 4d-flow), have not yet been leveraged to study SRS treatment effects on AVMs. ${ }^{9}$

4D Flow MRI acquires time-resolved phase-contrast data with $3 \mathrm{D}$ velocity-encoding throughout the cardiac cycle, pro-

Received August 28, 2017; accepted after revision November 13.

From the Department of Radiology (C.Q.L., A.H., J.H., N.F.), University of California, San Diego, San Diego, California; and Department of Radiation Medicine and Applied Sciences (J.H.-G.), University of California, San Diego, La Jolla, California.

Paper previously presented at: Annual Meeting of the American Society of Neuroradiology and the Foundation of the ASNR Symposium, April 22-27, 2017; Long Beach, California.

Please address correspondence to Charles Q. Li, MD, Department of Radiology, University of California, San Diego, 200 W Arbor Dr, MC 8756, San Diego, CA 92103; e-mail: charlesqli@alumni.ucsd.edu

$\square$ Indicates article with supplemental on-line video.

http://dx.doi.org/10.3174/ajnr.A5535 ducing a $4 \mathrm{D}$ dataset of velocity vectors. This $4 \mathrm{D}$ dataset can be retrospectively analyzed to measure flow in any direction, as well as to calculate numerous other fluid dynamic metrics such as velocity, pressure gradients, vorticity, wall shear stress, turbulence, and so forth. ${ }^{10}$ Flow vectors can also be rendered in $3 \mathrm{D}$ in various display formats for qualitative visualization. ${ }^{11}$

We report imaging and hemodynamic data from serial $4 \mathrm{D}$ Flow MRI of a Spetzler-Martin grade III AVM treated with SRS as a proof-of-concept application of 4D Flow, and we compare this technique with traditional MR imaging/MRA.

\section{MATERIALS AND METHODS}

A 19-year-old man was diagnosed with an unruptured $3.5 \times$ $2.9 \times 2.5 \mathrm{~cm}$ Spetzler-Martin grade III AVM in the medial left temporal lobe on a trauma work-up. Conventional angiography showed primary arterial supply from the left MCA with secondary contribution from the left posterior cerebral artery (Fig $1 A,-B$ ). Venous drainage was solely via the left basal vein of Rosenthal (Fig $1 C)$. The nidus was treated with single-fraction SRS to a prescription dose of $1800 \mathrm{cGy}$ (mean dose, $2000 \mathrm{cGy}$; maximum, dose $2200 \mathrm{cGy}$ ) using a linear accelerator-based volumetric arc therapy technique. The patient experienced no acute or subacute complications.

Baseline MR imaging and serial follow-up MR imaging were performed at 1, 6, 12, and 20 months after SRS. All scans were obtained on a 3T Discovery 750 scanner (GE Healthcare, Milwaukee, Wisconsin), including simple 4-point-encoded 4D Flow MRI with variable-density Poisson disc undersampling, ${ }^{11,12}$ with E-SPIRiT (eigenvector-based iTerative Selfconsistent Parallel Imaging Reconstruction) combined parallel imaging and compressed-sensing image reconstruction. ${ }^{13,14}$ 

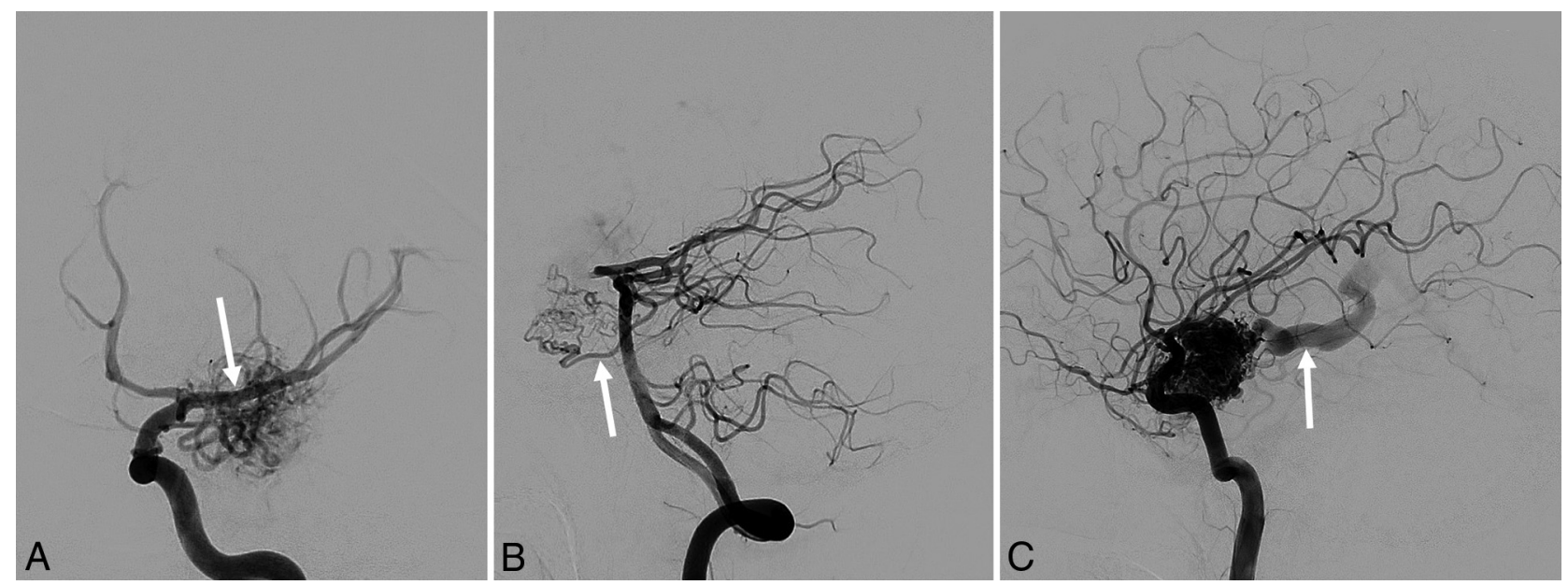

FIG 1. Conventional angiography of a left temporal lobe AVM. Early arterial phases show primarily MCA supply (arrow) on a left frontal oblique left ICA injection $(A)$, with secondary posterior cerebral artery supply via a small branch artery (arrow) on a lateral left vertebral artery injection $(B)$. Late arterial phase $(C)$ shows early opacification of the left basal vein of Rosenthal, the exclusive venous drainage (arrow).

4D Flow MRI acquisition parameters

\begin{tabular}{ll}
\hline \multicolumn{1}{c}{ Parameter } & \\
\hline Contrast volume & $15-20 \mathrm{~mL}$ of gadobenic acid \\
Voxel size & $1.12 \times 0.98 \times 1.60$ to $1.16 \times 1.02 \times 1.80 \mathrm{~mm}$ \\
Flip angle & $15^{\circ}$ \\
TR & $4.96-5.05 \mathrm{sec}$ \\
TE & $2.40-2.57 \mathrm{~ms}$ \\
Scan time & $7 \mathrm{~min} 45 \mathrm{sec}$ to $9 \mathrm{~min} 3 \mathrm{sec}$ \\
Velocity encoding & $100-200 \mathrm{~cm} / \mathrm{s}$ \\
Bandwidth & $62 \mathrm{kHz}$ \\
\hline
\end{tabular}

The combination of variable-density Poisson undersampling and E-SPIRiT reconstruction provides the mechanism for compressed sensing, which preserves signal to noise while reducing 4D Flow acquisition time. The parallel imaging acceleration factor was 3.6 overall (1.8 in phase-encode and 2.0 in slice-encode directions). Additional specific acquisition parameters are listed in the Table. At each time point, blood flow (liters/minute) was measured in bilateral distal ICAs, bilateral proximal MCAs, and the draining left basal vein of Rosenthal.

\section{RESULTS}

In the 20 months following SRS, the patient's left temporal lobe AVM nidus gradually decreased in size from approximately $3.5 \times$ $2.9 \times 2.5 \mathrm{~cm}$ to $2.0 \times 1.5 \times 1.3 \mathrm{~cm}$, as measured on $3 \mathrm{D}$ time-offlight MRA. Time-resolved color-coded 3D volumetric renderings of $4 \mathrm{D}$ Flow velocity data demonstrated visibly decreasing flow velocity in the left MCA, the dominant arterial supply, denoted by decreasing red and yellow velocity vectors and increasing green velocity vectors (Fig 2). Video renderings of 4D Flow data collected throughout the cardiac cycle are available in the On-line Videos.

Blood flow measurements performed using 4D Flow data initially showed asymmetrically greater flow to the left MCA and ICA compared with the contralateral side 1 month posttreatment, which began to normalize by the 6-month follow-up examination. In contrast, flow in the right anterior circulation slightly increased between the 1- and 6-month follow-ups.

By the 20-month follow-up scan, flow in the left MCA and ICA had decreased by $51 \%$ ( 0.51 to $0.25 \mathrm{~L} / \mathrm{min})$ and $34 \%$ ( 0.59 to 0.39 $\mathrm{L} / \mathrm{min}$ ) compared with initial values, respectively, while the net change in right MCA and ICA flow was $<11 \%$ (Fig $3 A$ ). Blood flow in the draining vein also decreased with time, from 0.25 to $0.07 \mathrm{~L} / \mathrm{min}$ by the 20 -month follow-up, a net reduction of $80 \%$ (Fig 3B).

\section{DISCUSSION}

Treatment response following SRS therapy for AVMs is most commonly assessed with conventional MR imaging and MRA techniques, which are tailored to evaluate brain parenchyma and vascular anatomy. This case of a patient with an unruptured AVM treated with curative SRS demonstrates the ability of 4D Flow MRI to quantify radiation therapy-induced hemodynamic changes that are not captured by traditional anatomic imaging modalities.

While radiation-induced endothelial hyperproliferation typically results in a 1- to 3-year latency period between SRS and AVM nidus obliteration, we quantified a decrease in blood flow through a left temporal lobe AVM as early as 6 months after treatment, previously unreported using MRA techniques. We also quantified an increase in flow to the contralateral anterior circulation at the 6-month follow-up, which may suggest reversal of a left-to-right steal phenomenon as flow to the AVM decreased. ${ }^{15}$ These findings underscore the ability of $4 \mathrm{D}$ Flow MRI to quantify flow dynamics across the entire brain in 1 scan and represent the first application of this technique in the evaluation of SRS treatment effects on AVMs. ${ }^{16}$

Future studies will follow cohorts of patients to explore the relationship between flow dynamics measured by $4 \mathrm{D}$ Flow MRI and long-term outcomes, such as hemorrhage risk, length of latency period, and rate of eventual obliteration. Additional hemodynamic measures, such as intravascular pressure gradients, turbulence, and wall shear stress can be examined as well. Flow-mapping capabilities could evaluate changes in flow connectivity in complex AVMs with multiple feeding and draining vessels and perhaps help to further optimize SRS treatment targets. ${ }^{17}$

AJNR Am J Neuroradiol 39:678-81 Apr 2018 www.ajnr.org 


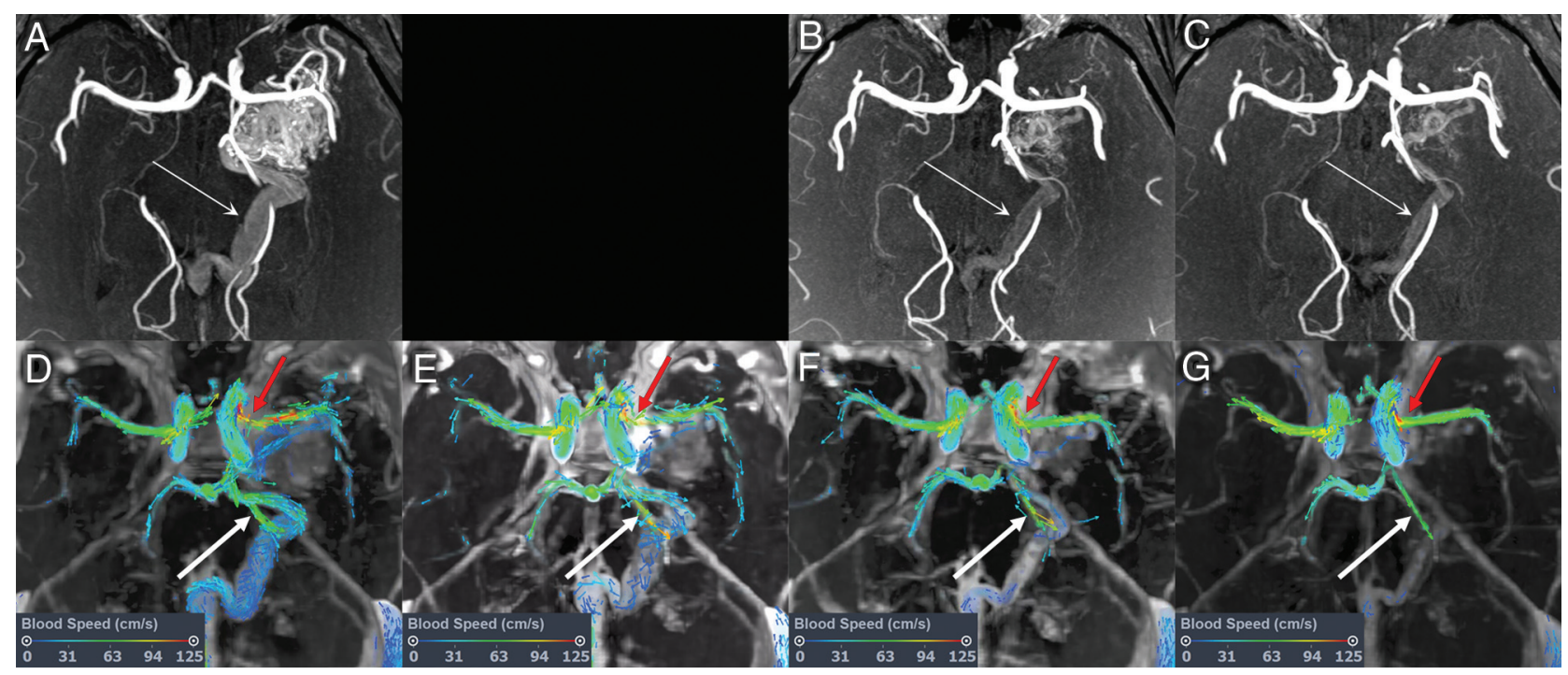

FIG 2. Conventional 3D time-of-flight MRA (upper row) and 4D Flow MRI (lower row) during a 20-month follow-up course after SRS. Scans were acquired at $1(A$ and $D), 6(E), 12$ ( $B$ and $F)$, and 20 ( $C$ and $G)$ months following SRS (MRA was not performed at the 6-month follow-up). Conventional sequences show a gradual decrease in size of the left temporal lobe AVM nidus, with decreasing distention of the draining vein (thin white arrow). 4D Flow MRI 1 month after SRS (D) shows asymmetrically greater flow in the left MCA (thick red arrow) and posterior cerebral artery feeding vessels (thick white arrow), as well as in the distended draining vein. The left MCA flow velocity gradually decreases with time $(D-G)$.
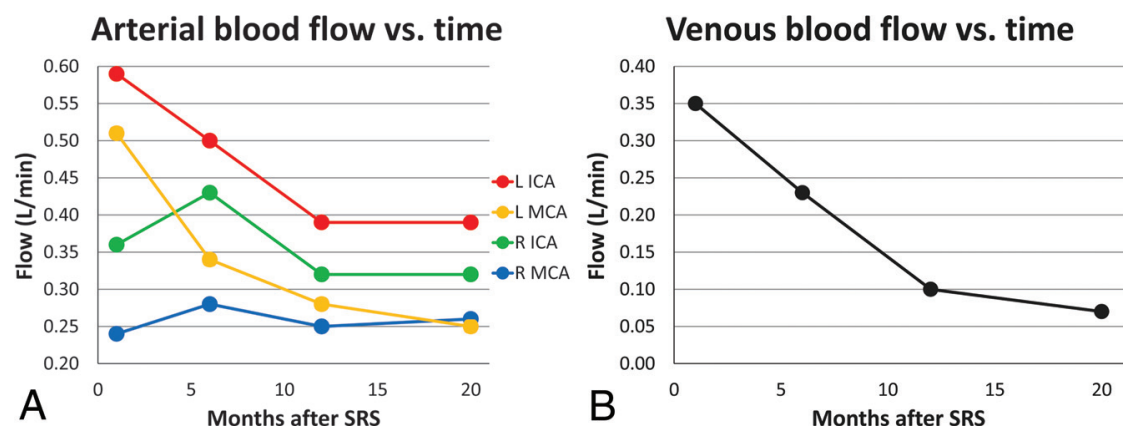

FIG 3. Blood flow in the anterior circulation $(A)$ and draining vein $(B)$ measured by 4D Flow over a 20-month follow-up after SRS. At the 6-month follow-up, arterial flow decreased most dramatically in the left MCA. Flow in the left MCA, left ICA, and draining vein continued to decrease throughout the posttreatment course.

Disclosures: Albert Hsiao_ UNRELATED: Consultancy: Arterys; Grants/Grants Pending: GE Healthcare*; Patents (Planned, Pending or Issued): Stanford University; Royalties: Stanford University; Stock/Stock Options: Arterys*. *Money paid to the institution.

\section{REFERENCES}

1. Lunsford LD, Kondziolka D, Flickinger JC, et al. Stereotactic radiosurgery for arteriovenous malformations of the brain. J Neurosurg 1991;75:512-24 CrossRef Medline

2. van Beijnum J, van der Worp HB, Buis DR, et al. Treatment of brain arteriovenous malformations: a systematic review and meta-analysis. JAMA 2011;306:2011-19 CrossRef Medline

3. Kano H, Kondziolka D, Flickinger JC, et al. Stereotactic radiosurgery for arteriovenous malformations, Part 3: outcome predictors and risks after repeat radiosurgery. J Neurosurg 2012;116:21-32 CrossRef Medline

4. O'Connor TE, Friedman WA. Magnetic resonance imaging assessment of cerebral arteriovenous malformation obliteration after stereotactic radiosurgery. Neurosurgery 2013;73:761-66 CrossRef Medline

5. Pollock BE, Kondziolka D, Flickinger JC, et al. Magnetic resonance imaging: an accurate method to evaluate arteriovenous malformations after stereotactic radiosurgery. J Neurosurg 1996;85:1044-49 CrossRef Medline
6. Kihlström L, Guo WY, Karlsson B, et al. Magnetic resonance imaging of obliterated arteriovenous malformations up to 23 years after radiosurgery. J Neurosurg 1997;86:589-93 CrossRef Medline

7. Buis DR, Bot JC, Barkhof F, et al. The predictive value of 3D timeof-flight MR angiography in assessment of brain arteriovenous malformation obliteration after radiosurgery. AJNR Am J Neuroradiol 2012;33:232-38 CrossRef Medline

8. Lee CC, Reardon MA, Ball BZ, et al. The predictive value of magnetic resonance imaging in evaluating intracranial arteriovenous malformation obliteration after stereotactic radiosurgery. J Neurosurg 2015;123:136-44 CrossRef Medline

9. Pereira VM, Delattre B, Brina O, et al. 4D flow MRI in neuroradiology: techniques and applications. Top Magn Reson Imaging 2016;25:81-87 CrossRef Medline

10. Markl M, Frydrychowicz A, Kozerke S, et al. 4D flow MRI. J Magn Reson Imaging 2012;36:1015-36 CrossRef Medline

11. Hsiao A, Lustig M, Alley MT, et al. Evaluation of valvular insufficiency and shunts with parallel-imaging compressed-sensing 4D phase-contrast MR imaging with stereoscopic 3D velocity-fusion volume-rendered visualization. Radiology 2012;265:87-95 CrossRef Medline

12. Hsiao A, Alley MT, Massaband P, et al. Improved cardiovascular 
flow quantification with time-resolved volumetric phase-contrast MRI. Pediatr Radiol 2011;41:711-20 CrossRef Medline

13. Uecker M, Lai P, Murphy MJ, et al. ESPIRiT-an eigenvalue approach to autocalibrating parallel MRI: where SENSE meets GRAPPA. Magn Reson Med 2014;71:990-1001 CrossRef Medline

14. Murphy M, Alley M, Demmel J, et al. Fast $\ell_{1}$-SPIRiT compressed sensing parallel imaging MRI: scalable parallel implementation and clinically feasible runtime. IEEE Trans Med Imaging 2012;31: 1250-62 CrossRef Medline

15. Homan RW, Devous MD Sr, Stokely EM, et al. Quantification of intracerebral steal in patients with arteriovenous malformation. Arch Neurol 1986;43:779-85 CrossRef Medline

16. Ansari SA, Schnell S, Carroll T, et al. Intracranial 4D flow MRI: toward individualized assessment of arteriovenous malformation hemodynamics and treatment-induced changes. AJNR Am J Neuroradiol 2013;34:1922-28 CrossRef Medline

17. Wu C, Schnell S, Markl M, et al. Combined DSA and 4D flow demonstrate overt alterations of vascular geometry and hemodynamics in an unusually complex cerebral AVM. Clin Neuroradiol 2016;26: 471-75 CrossRef Medline 